\title{
Media and Communication: Why Another Journal?
}

\author{
Bradley S. Greenberg ${ }^{1, *}$, Hannes Haas ${ }^{2, *}$ and Elisabeth Klaus ${ }^{3, *}$ \\ ${ }^{1}$ College of Communication Arts \& Sciences, Michigan State University, Michigan 48824, USA; E-Mail: bradg@msu.edu \\ 2 Department of Communication, University of Vienna, 1090 Vienna, Austria; E-Mail: hannes.haas@univie.ac.at \\ ${ }^{3}$ Department of Communication, University of Salzburg, 5020 Salzburg, Austria; E-Mail: elisabeth.klaus@sbg.ac.at \\ * Corresponding authors
}

Submitted: 29 July 2013 | Published: 5 August 2013

Indeed, there are some three dozen English-language journals now that deal with one or another or multiple aspects of the field of media and (mass) communication. Would another journal not be redundant? We think not. Media and Communication, henceforth shortened to $\mathrm{MaC}$, will possess a specific combination of attributes that are not replicated elsewhere and together result in the unique position of the journal.

$\mathrm{MaC}$ will be timely. It will be published when the editors believe there is a critical collection of articles to publish. It will not be known as quarterly or semiannual, but as timely. No 1-year or 2-year or longer delays in making your refereed work available to the academic community.

$\mathrm{MaC}$ will be online. That is obvious from the fact that it can be 'published' when desired. This carries with it the attribute of nearly universal accessibility. Clearly the venerable journals in communication have come to recognize the need to be online, and thus convert. We need no conversion. We begin and end online.

$\mathrm{MaC}$ will be international. Other journals make this claim. Please examine the roster of editors and scholarly reviewers who have been assembled by the publisher of MaC. They represent more than a dozen countries and languages. It is their responsibility not only to review manuscripts, but also to solicit quality scholarship within their geographic region.

$\mathrm{MaC}$ will be intercultural. The well-known international journals in communication largely focus on the Anglo-American communities. We will try to pub- lish innovative research done in other regions of the world that right now are marginalized within the field.

$\mathrm{MaC}$ will be eclectic and multi-faceted. Other journals tend to have a much narrower focus, either in subject matter or in favored methodology. We believe that the editors and reviewers of $\mathrm{MaC}$ have the abilities to recognize quality scholarship regardless of its substantive focus and/or its choice of methods. We conceive of media and communication research as an integrative discipline at the intersection of many other scientific fields.

$\mathrm{MaC}$ will be open-minded and cosmopolitan. We will provide a forum for new and challenging ideas in the field that focus on the transformation of media and communication and its social and cultural relevance in a globalized world.

$\mathrm{MaC}$ will be free. Open access for readers is selfexplanatory. Libraries around the world will be able to subscribe to the journal for free, thus countering the immense costs that the big publishers are imposing on the free access to knowledge.

$\mathrm{MaC}$ will be fair to its authors. Our publisher pursues a new open-access model that enables not only established scholars but also young professionals and those from outside an institutional setting to publish their relevant contributions at relatively low cost. Our authors will always remain in possession of the copyright to their work.

Support for these assertions will come with time, in the form of high quality scholarly presentations. 